\title{
Virologic outcomes of second-line antiretroviral therapy in Eastern European country of Georgia
}

\author{
Nikoloz Chkhartishvili ${ }^{1 *}$, Lali Sharvadze ${ }^{1,2}$, Natia Dvali ${ }^{1}$, Marine Karchava ${ }^{1}$, Nino Rukhadze ${ }^{1}$, Maia Lomtadze ${ }^{1}$, \\ Otar Chokoshvili ${ }^{1}$ and Tengiz Tsertsvadze ${ }^{1,2}$
}

\begin{abstract}
Background: Data on the effectiveness of second-line antiretroviral therapy (ART) in resource-limited countries of Eastern Europe is limited. Objective of this study was to evaluate virological outcomes of second-line ART in Georgia.

Methods: We conducted retrospective analysis using routinely available program data. Study included adult HIV-infected patients with confirmed HIV drug resistance, who were switched to second-line ART from August 2005 to December 2010. Patients were followed until July 1, 2011. Primary outcome was achievement of viral suppression. Demographic, clinical, laboratory and adherence data were abstracted from medical and program records. Adherence was expressed as percentage based on medication refill data, and was calculated as days supply of medications dispensed divided by days between prescription fills. Predictors of primary outcome were assessed in modified Poisson regression analysis.
\end{abstract}

Results: A total of 84 patients were included in the study. Among them $71.4 \%$ were men and $62 \%$ had history of IDU. All patients were receiving non-nucleoside reverse transcriptase based regimen as initial ART. The mean 6-month adherence prior to virologic failure was $75 \%$, with $31 \%$ of patients showing $100 \%$ adherence. All patients were switched to protease inhibitor based regimens. Patients were followed for median 27 months. Over this period 9 (10.7\%) patients died. Among 80 patients remaining alive at least 6 month after ART regimen switch, 72 (90\%) patients ever reached undetectable viral load. The mean first 6-month adherence on second-line treatment was $81 \%$, with $47.5 \%$ of patients showing $100 \%$ adherence. The proportion of patients achieving viral suppression after 6, 12, 24 and 36 months of second-line ART did not vary significantly ranging from 79 to $83 \%$. Percentage of IDUs achieving viral suppression ranged from $75 \%$ and $83 \%$. Factors associated with failure to achieve viral suppression at 6 -months of second-line ART were: adherence $<80 \%$ (Risk ratio [RR] 5.09, 95\% Cl: 1.89-13.70) and viral load $>100,000$ at the time of treatment failure (RR 3.39, 95\% Cl: 1.46-7.89).

Conclusions: The study demonstrated favourable virological outcomes of the second-line ART in Georgia. Majority of patients, including IDUs, achieved sustained virological response over 36 month period. The findings highlight the need of improving adherence.

Keywords: HIV, Antiretroviral therapy, Second-line ART, Eastern Europe

\section{Background}

The number of people receiving antiretroviral therapy (ART) in resource limited settings is climbing rapidly. At the end of 2012 estimated 9.7 million people in low- and middle-income countries had access to ART, representing 40-fold increase over the last decade [1]. As scale-up of ART continues growing number of

\footnotetext{
* Correspondence: nc@aidscenter.ge

'Infectious Diseases, AIDS and Clinical Immunology Research Center, 16 Al. Kazbegi Avenue, Tbilisi 0160, Georgia

Full list of author information is available at the end of the article
}

patients experience treatment failure increasing demand on second-line regimens [2-4].

There is limited data on the use of second-line ART in Eastern European region, where HIV epidemic is primarily driven by injection drug users (IDU). Although region has low ART coverage, the absolute number of persons accessing the lifesaving therapy has been annually increasing and reached nearly 200,000 in 2012 [1]. Better understanding of second-line ART delivery in the region will be important to ensure its long-term effectiveness.

Georgia is an Eastern European nation located in the Caucasus between Turkey and Russia. Similar to other 
countries in the region the HIV epidemic in Georgia has been concentrated around IDUs, accounting for 55\% of total reported cases of HIV infection. Since 2004, through the support from the Global Fund to Fight AIDS, Tuberculosis and Malaria Georgia has ensured universal access to ART. UNAIDS estimates conform that Georgia has the highest ART coverage in the region [1]. Previously we showed that ART substantially reduced mortality and increased survival in Georgia [5,6]. The objective of the current study was to evaluate virologic outcomes of second-line ART in the country.

\section{Methods}

We conducted retrospective analysis using routinely available program data. Study included adult (age $\geq 18$ years) HIV-infected patients enrolled in national HIV/AIDS treatment and care program. Patients with confirmed HIV drug resistance, who were switched to second-line ART regimens from August 2005 to December 2010 were included in the analysis. Patients were followed until July 1, 2011.

Georgia's national HIV/AIDS treatment and care program provides HIV related medical services to all diagnosed HIV patients. The program is coordinated by the Infectious Diseases, AIDS and Clinical Immunology Research Center (IDACIRC), which is country's referral institution for HIV diagnosis, treatment and care. Patients receive services at IDACIRC clinic and three dedicated regional facilities.

Provision of ART in Georgia is governed by national HIV/AIDS treatment and care guidelines, which was first developed in 2004. During the study period (2005-2010) ART was recommended at CD4 count $\leq 200$ cells $/ \mathrm{mm}^{3}$. The recommended initial regimen consisted of two nucleoside reverse transcriptase inhibitors (NRTI) and one non-nucleoside reverse transcriptase inhibitor (NNRTI). Zidvudine (AZT) + lamivudine (3TC) has been preferred NRTI component since 2004. Stavudine (d4T) was phased out after 2007 revision of national guidelines, and was replaced by abacavir $(\mathrm{ABC})+$ lamivudine $(3 \mathrm{TC})$ or tenofovir (TDF) + emtricitabine (FTC). Efavirenz (EFV) has been the preferred NNRTI with nevirapine (NVP) being recommended as an alternative to EFV.

According to national guidelines follow-up of patients on ART relied on regular monitoring of CD4 count and HIV viral load. HIV drug resistance was performed routinely among patients with virologic failure, defined as confirmed plasma HIV RNA $>400$ copies/ml 6 months after starting therapy or after undetectable viral load while on therapy. Results of drug résistance testing were used for selection of second-line therapy.

During the study period plasma HIV RNA levels were measured using either Amplicor HIV-1 Monitor test, version 1.5 (Roche Molecular Diagnostics, Germany) or the real-time PCR assay COBAS TaqMan HIV-1 test (Roche Molecular Diagnostics, Germany). For genotypic resistance testing the TruGene HIV-1 Genotyping Kit was employed according to the manufacturer's instructions using OpenGene DNA Sequencing System (Siemens Medical Solutions Diagnostics, Germany). The Stanford University algorithm (http://hivdb.stanford.edu/) were used for resistance interpretation.

Demographic, epidemiological, clinical and laboratory data were extracted from program and medical records. Baseline characteristics were collected at the time point when patient experienced virologic failure. Adherence was expressed as percentage based on medication refill data,

Table 1 Patient characteristics at the time of virological failure on initial ART $(n=84)$

\begin{tabular}{|c|c|}
\hline & $\mathrm{n}=84$ \\
\hline Age, median years (IQR) & $37(34-44)$ \\
\hline \multicolumn{2}{|l|}{ Sex, $n(\%)$} \\
\hline Men & $60(71.4)$ \\
\hline Women & $24(28.6)$ \\
\hline \multicolumn{2}{|l|}{ Mode of HIV transmission, $\mathrm{n}(\%)$} \\
\hline Injection drug use & $52(61.9)$ \\
\hline Heterosexual contact & $28(33.3)$ \\
\hline Male-to-male sex & $2(2.4)$ \\
\hline Blood recipient & $2(2.4)$ \\
\hline \multicolumn{2}{|l|}{ HCV infection, $n(\%)$} \\
\hline anti-HCV+ & $45(53.6)$ \\
\hline anti-HCV- & $39(46.4)$ \\
\hline \multicolumn{2}{|l|}{ Tuberculosis, n (\%) } \\
\hline History of TB & $35(41.7)$ \\
\hline No history of TB & $49(58.3)$ \\
\hline \multicolumn{2}{|l|}{ ART regimen at failure, $n(\%)$} \\
\hline Zidovudine + Lamivudine + Efavirenz & $39(46.4)$ \\
\hline Zidovudine + Lamivudine + Nevirapine & $14(16.7)$ \\
\hline Abacavir + Lamivudine + Efavirenz & $17(20.2)$ \\
\hline Abacavir + Lamivudine + Nevirapine & $3(3.6)$ \\
\hline Stavudine + Lamivudine + Efavirenz & $7(8.3)$ \\
\hline Stavudine + Lamivudine + Nevirapine & $2(2.4)$ \\
\hline Tenofovir + Emtricitabine + Efavirenz & $2(2.4)$ \\
\hline \multicolumn{2}{|l|}{ 6-month adherence prior to failure, $n(\%)$} \\
\hline$<80 \%$ & $36(42.9)$ \\
\hline $80-<100 \%$ & $22(26.2)$ \\
\hline $100 \%$ & $26(30.9)$ \\
\hline Time to failure, median (IQR) & $18(12-34)$ \\
\hline Viral load at failure, median copies/ml (IQR) & $23600(8365-126000$ \\
\hline Number of resistant mutations, median (IQR) & $2(1-4)$ \\
\hline \multicolumn{2}{|l|}{ Drug class resistance, $\mathrm{n}(\%)$} \\
\hline Single class (NRTI or NNRTI) & $12(14.3)$ \\
\hline Dual class (NRTI + NNRTI) & $72(85.7)$ \\
\hline
\end{tabular}




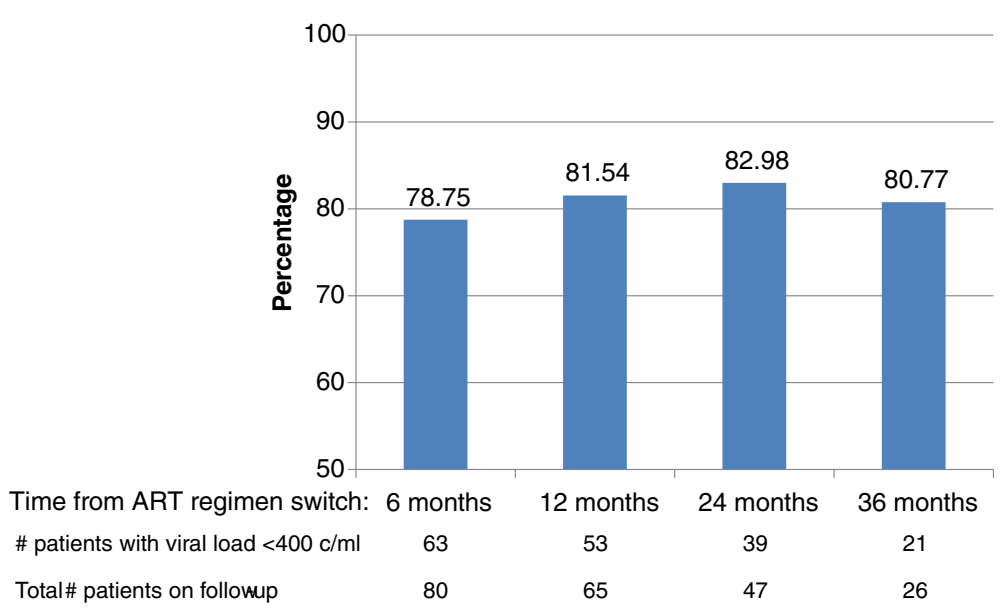

Figure 1 The proportion of patients achieving viral suppression after initiating second-line antiretroviral therapy.

and was calculated as days supply of medications dispensed divided by days between prescription fills. The primary outcome was proportion of patients achieving viral suppression $(<400$ copies $/ \mathrm{ml})$ after the switch to second line ART. Predictors of primary outcome were assessed in modified Poisson regression analysis [7]. All statistical analyses were performed using SAS 9.2.

Study was approved by the Institutional Review Board of IDACIRC.

\section{Results}

Table 1 summarizes characteristics of 84 patients included in the analysis. Among them the majority were men (71.4\%) and 62\% had history of IDU. At the time of virologic failure on initial ART, all patients were receiving NNRTI based regimen, and vast majority (77\%) were on EFV (77\%). AZT + 3TC was the most common NRTI backbone, prescribed to $63 \%$ of patients. The mean 6-month medication refill adherence prior to virologic failure was $75 \%$, with $31 \%$ of patients timely picking-up their prescription. None of the patients had virus with resistance mutations to PIs, and $86 \%$ had NRTI/NNRTI dual class-resistant viruses. All patients were switched to PI-containing regimens, including $62(73.8 \%)$ to ritonavir boosted Lopinvair (LPV/r)-based and 22 (26.2\%) to ritonavir boosted Atazanavir $(\mathrm{ATV} / \mathrm{r})$-based regimens.

Patients were followed for median 27 (Interquartile range [IQR]: 13-41) months. Over this period 9 (10.7\%) patients died in median 6 (IQR: 2-8) months after treatment switch, four of them died within 6 month period.

Among 80 patients remaining alive at least 6 month after ART regimen switch, 72 (90\%) patients ever achieved viral suppression after median 7 (IQR: 5-10) months. The mean first 6-month adherence on second-line treatment was $81 \%$, with $47.5 \%$ of patients showing $100 \%$ adherence. The proportion of patients achieving viral suppression after 6, 12, 24 and 36 months of second-line ART did not vary significantly ranging from 79 to $83 \%$ (Figure 1). Percentage of IDUs achieving viral suppression ranged from $75 \%$ and $83 \%$. During the follow-up five patients met the criteria of virologic failure and were tested for HIV drug resistance. None of the strains evaluated carried major PI mutations.

Factors associated with failure to achieve viral suppression after 6 months of regimen modification were evaluated in multivariate analysis. Lower adherence $<80 \%$ (Risk ratio [RR] 5.09, 95\% Confidence interval [CI]: 1.89-13.70) and viral load of greater than 100,000 at the time of treatment failure (RR 3.39, 95\% CI: 1.46-7.89) were significantly associated with detectable viral load (Table 2). Neither gender nor mode of HIV transmission showed association with the outcome.

\section{Discussion}

Findings of this analysis indicate that majority of patients with HIV drug resistance in Georgia achieve and maintain viral suppression after switching to second-line therapy. To the best of our knowledge this is the first published study that evaluated outcomes of second-line ART in Eastern Europe, therefore regional comparisons cannot be made. Early virologic outcomes seen in our study were generally consistent with findings from other resource-limited countries, primarily from Africa and Asia, with approximately $80 \%$ of patients on second-line ART achieving viral suppression at 6 and 12 months [8-12]. Recent meta-analysis of 19 studies found that that proportion of patients achieving viral suppression dropped from $78 \%$ at 6 months to $62 \%$ at 36 months of starting second-line regimen [8]. However, there was substantially heterogeneity between studies, with some studies reporting success rates of around and more than $90 \%$ [13-16]. In our study more than $80 \%$ of patients consistently had undetectable levels of viral load after 6 months of second-line ART. 
Table 2 Factors associated with failure to achieve viral suppression 6 months after switching ART regimen $(n=80)$

\begin{tabular}{|c|c|c|c|c|}
\hline & \multirow[t]{3}{*}{ Total $\mathbf{N}$} & \multicolumn{3}{|c|}{ Detectable viral load } \\
\hline & & n (\%) & Bivariate & Multivariate \\
\hline & & & RR (95\% CI) & $\mathrm{RR}(95 \% \mathrm{Cl})$ \\
\hline \multicolumn{5}{|l|}{ Age } \\
\hline$<37$ years & 35 & $7(20.0)$ & $0.90(0.38-2.12)$ & \\
\hline$\geq 37$ years & 45 & $10(22.2)$ & 1 & \\
\hline \multicolumn{5}{|l|}{ Sex } \\
\hline Men & 57 & $13(22.8)$ & $1.31(0.48-3.60)$ & $0.50(0.17-1.45)$ \\
\hline Women & 23 & $4(17.4)$ & 1 & 1 \\
\hline \multicolumn{5}{|l|}{ Mode of HIV transmission } \\
\hline IDU & 49 & $12(24.5)$ & $1.52(0.59-3.89)$ & $1.34(0.64-2.83)$ \\
\hline non-IDU & 31 & $5(16.1)$ & 1 & 1 \\
\hline \multicolumn{5}{|l|}{ HCV infection } \\
\hline anti-HCV+ & 42 & $9(21.4)$ & $1.02(0.44-2.37)$ & \\
\hline anti-HCV- & 38 & $8(21.1)$ & 1 & \\
\hline \multicolumn{5}{|l|}{ Tuberculosis } \\
\hline History of TB & 31 & $6(19.4)$ & $0.86(0.36-2.09)$ & \\
\hline No history of TB & 49 & $11(22.5)$ & 1 & \\
\hline \multicolumn{5}{|c|}{ Viral load at failure on initial ART } \\
\hline$\geq 100,000$ & 21 & $9(42.9)$ & $3.16(1.40-7.12)$ & $3.39(1.46-7.89)$ \\
\hline$<100,000$ & 59 & $8(13.6)$ & 1 & 1 \\
\hline \multicolumn{5}{|l|}{ ART regimen after switch } \\
\hline ATV/r-based & 20 & $4(20.0)$ & $0.92(0.34-2.51)$ & \\
\hline LPV/r-based & 60 & $13(21.7)$ & 1 & \\
\hline \multicolumn{5}{|c|}{ 6-month adherence after regimen switch } \\
\hline$<80 \%$ & 19 & $10(52.6)$ & $5.01(1.80-13.87)$ & $5.09(1.89-13.70)$ \\
\hline $80-<100 \%$ & 23 & $3(13.0)$ & $1.24(0.30-5.05)$ & $1.48(0.36-6.12)$ \\
\hline $100 \%$ & 38 & $4(10.5)$ & 1 & 1 \\
\hline \multicolumn{5}{|c|}{ Number of resistance mutations } \\
\hline$>2$ mutations & 21 & $3(14.3)$ & $0.60(0.19-1.89)$ & \\
\hline$\leq 2$ mutations & 59 & $14(23.7)$ & 1 & \\
\hline \multicolumn{5}{|l|}{ Drug class resistance } \\
\hline Single class (NRTI or NNRTI) & 11 & $3(27.3)$ & $1.34(0.46-3.93)$ & \\
\hline Dual class (NRTI + NNRTI) & 69 & $14(20.3)$ & 1 & \\
\hline
\end{tabular}

Multivariate analysis showed that adherence of $<80 \%$ was the strongest predictor of failure to achieve viral suppression after 6 months of second-line ART (RR 5.09, 95\% CI: 1.89-13.70). There was no statistically significant difference between adherence levels of $100 \%$ and $80-<100 \%$. Also, none of five patients screened for HIV drug resistance after failure of second-line ART harbored the viruses with major PI mutations. These data confirm that ritonavir-boosted PI regimens in Georgian settings are 'forgiving' as seen elsewhere [17] and that non-adherence is the primary reason of virologic failure, but not resistance. Similar findings were reported by Murphy and colleagues [10]. Although overall adherence improved after treatment modification, efforts are still needed to ensure high levels of adherence in a long term in all patients.

The reported rates of mortality among patients on second-line ART varied substantially, ranging from 3\% to $16 \%$ [18-21]. In our study $11 \%$ of patients died over the follow-up, including four patients died within 6 months after the switch. It is unlikely that mortality in our study was directly related to virologic failure to initial regimen. Routine use of viral load in Georgia and low number of drug resistance mutation at the time failure indicates that regimens were modified timely. Analysis of causes of death 
also does not support linkage between virologic failure and mortality in our study. Six (67\%) of 9 deaths reported were attributable to non-AIDS related causes, including end stage liver disease and cardiovascular disease.

Our study provides evidence that persons with history of IDU can achieve optimal treatment outcomes. Percentage of IDUs achieving viral suppression ranged from $75 \%$ and $83 \%$ after initial treatment modification. Also, history of IDU was not associated with virologic failure in multivariate analysis. This has important implications for the Eastern European region, where IDUs are often face barriers for accessing ART [22]. Our study clearly shows that IDUs can achieve optimal treatment outcomes and that no one should be withheld from therapy. Factors that might have contributed to optimal outcomes among persons with history of IDU include environment with free HIV-related medical care, availability of adherence support services and methadone substation therapy.

Our study is subject to limitations. First this is the small sample size, which limited statistical power and generalizability of our findings. Also, we conducted retrospective analysis utilizing routinely available data, thus there might have been unmeasured factors that influenced the outcomes. We only had information on history of IDU, based on HIV transmission category. Information on ongoing drug abuse may have influenced comparisons. Viral load was measured by physician's discretion and we extracted measurements closest to the time intervals studied.

\section{Conclusions}

In conclusion, our study shows that second-line therapy is effective in IDU-driven epidemic setting of Georgia. More than $80 \%$ of patients, including those with history of IDU, maintained viral suppression over 36 months period. Although adherence improved after switching to second-line ART, it showed to be the most important factor associated with virologic outcome. Efforts are needed to ensure durability of adherence and hence viral suppression. Persons with history of IDU can fully benefit from second-line ART.

\section{Abbreviations}

ART: Antiretroviral therapy; HIV: Human immunodeficiency virus; AIDS: Acquired immune deficiency syndrome; IDU: Injection drug use; NRTI: Nucleoside reverse transcriptase inhibitor; NNRTI: Non-nucleoside reverse transcriptase inhibitor; PI: Protease inhibitor; IQR: Interquartile range; ATV/r: Atazanavir/ritonavir; LPV/r: Lopinavir/ritonavir; IDACIRC: Infectious Diseases AIDS and Clinical Immunology Research Center.

\section{Competing interests}

The authors declare that they have no competing interest.

\section{Authors' contributions}

NC conducted statistical analysis and prepared the first draft of the manuscript. LS and TT contributed to concept and study design, data interpretation and also critically reviewed the manuscript. ND, MK, NR and $\mathrm{ML}$ contributed to data acquisition and edited the manuscript. OC prepared study datasets and contributed to data analysis. All authors read and approved the final manuscript.

\section{Author details}

${ }^{1}$ Infectious Diseases, AIDS and Clinical Immunology Research Center, 16 Al. Kazbegi Avenue, Tbilisi 0160, Georgia. ${ }^{2}$ I. Javakhishvili Tbilisi State University Faculty of Medicine, 16 Al. Kazbegi Avenue, Tbilisi 0160, Georgia.

Received: 20 March 2014 Accepted: 29 June 2014 Published: 7 July 2014

\section{References}

1. UNAIDS: Global report: UNAIDS report on the global AIDS epidemic 2013. Geneva: UNAIDS; 2013

2. Sungkanuparph S, Manosuthi W, Kiertiburanakul S, Piyavong B, Chumpathat $\mathrm{N}$, Chantratita W: Options for a second-line antiretroviral regimen for HIV type 1-infected patients whose initial regimen of a fixed-dose combination of stavudine, lamivudine, and nevirapine fails. Clin Infect Dis 2007, 44:447-452.

3. Pujades-Rodriguez M, O'Brien D, Humblet $P$, Calmy A: Second-line antiretroviral therapy in resource-limited settings: the experience of Medecins Sans Frontieres. Aids 2008, 22:1305-1312.

4. Hosseinipour MC, Gupta RK, Van Zyl G, Eron JJ, Nachega JB: Emergence of HIV Drug Resistance During First- and Second-Line Antiretroviral Therapy in Resource-Limited Settings. J Infect Dis 2013, 207:S49-S56.

5. Tsertsvadze T, Chkhartishvili N, Sharvadze L, Dvali N, Chokoshvili O, Gabunia P, Abutidze A, Nelson K, Dehovitz J, Del Rio C: Outcomes of Universal Access to Antiretroviral Therapy (ART) in Georgia. AIDS Res Treat 2011, 2011:621078.

6. Chkhartishvili N, Sharvadze L, Chokoshvili O, Bolokadze N, Rukhadze N, Kempker RR, Gamkrelidze A, Dehovitz JA, Del Rio C, Tsertsvadze T: Mortality and Causes of Death Among HIV-Infected Individuals in the Country of Georgia: 1989-2012. AIDS Res Hum Retroviruses 2014, 30:560-566.

7. McNutt LA, Wu C, Xue X, Hafner JP: Estimating the relative risk in cohort studies and clinical trials of common outcomes. Am J Epidemiol 2003, 157:940-943.

8. Ajose O, Mookerjee S, Mills EJ, Boulle A, Ford N: Treatment outcomes of patients on second-line antiretroviral therapy in resource-limited settings: a systematic review and meta-analysis. Aids 2012, 26:929-938.

9. Adetunji AA, Achenbach C, Feinglass J, Darin KM, Scarsi KK, Ekong E, Taiwo BO, Adewole IF, Murphy R: Optimizing Treatment Switch for Virologic Failure during First-Line Antiretroviral Therapy in Resource-Limited Settings. $J$ Int Assoc Provid AIDS Care 2012, 12:236-240.

10. Murphy RA, Sunpath H, Castilla C, Ebrahim S, Court R, Nguyen H, Kuritzkes DR Marconi VC, Nachega JB: Second-line antiretroviral therapy: long-term outcomes in South Africa. J Acquir Immune Defic Syndr 2012, 61:158-163.

11. Patel D, Desai M, Shah AN, Dikshit RK: Early outcome of second line antiretroviral therapy in treatment-experienced human immunodeficiency virus positive patients. Perspect Clin Res 2013, 4:215-220.

12. Schoffelen AF, Wensing AMJ, Tempelman HA, Geelen SPM, Hoepelman AIM, Barth RE: Sustained Virological Response on Second-Line Antiretroviral Therapy following Virological Failure in HIV-Infected Patients in Rural South Africa. PLoS One 2013, 8:e58526.

13. Ferradini L, Ouk V, Segeral O, Nouhin J, Dulioust A, Hak C, Fournier I, Lerolle N, Ngin S, Mean CV, Delfraissy JF, Nerrienet E: High efficacy of lopinavir/r-based second-line antiretroviral treatment after 24 months of follow up at ESTHER/ Calmette Hospital in Phnom Penh, Cambodia. J Int AIDS Soc 2011, 14:14.

14. Win MM, Maek-a-nantawat W, Phonrat B, Kiertiburanakul S, Sungkanuparph S: Virologic and Immunologic Outcomes of the Second-Line Regimens of Antiretroviral Therapy Among HIV-Infected Patients in Thailand. J Int Assoc Physicians AIDS Care 2011, 10:57-63.

15. Pujades-Rodriguez M, Balkan S, Arnould L, Brinkhof MA, Calmy A: Treatment failure and mortality factors in patients receiving second-line HIV therapy in resource-limited countries. JAMA 2010, 304:303-312.

16. Boulle A, Van Cutsem G, Hilderbrand K, Cragg C, Abrahams M, Mathee S, Ford N, Knight L, Osler M, Myers J, Goemaere E, Coetzee D, Maartens G: Seven-year experience of a primary care antiretroviral treatment programme in Khayelitsha, South Africa. Aids 2010, 24:563-572.

17. Shuter J: Forgiveness of non-adherence to HIV-1 antiretroviral therapy. J Antimicrob Chemother 2008, 61:769-773.

18. Castelnuovo B, John L, Lutwama F, Ronald A, Spacek LA, Bates M, Kamya MR, Colebunders R: Three-year outcome data of second-line antiretroviral therapy in Ugandan adults: good virological response but high rate of toxicity. J Int Assoc Physicians AIDS Care (Chic) 2009, 8:52-59. 
19. Fox MP, Ive P, Long L, Maskew M, Sanne I: High rates of survival, immune reconstitution, and virologic suppression on second-line antiretroviral therapy in South Africa. J Acquir Immune Defic Syndr 2010, 53:500-506.

20. Hosseinipour MC, Kumwenda JJ, Weigel R, Brown LB, Mzinganjira D,

Mhango B, Eron JJ, Phiri S, van Oosterhout JJ: Second-line treatment in the Malawi antiretroviral programme: high early mortality, but good outcomes in survivors, despite extensive drug resistance at baseline. HIV Med 2010, 11:510-518.

21. Charles M, Leger PD, Severe P, Guiteau C, Apollon A, Gulick RM, Johnson WD, Pape JW, Fitzgerald DW: Virologic, clinical and immunologic responses following failure of first-line antiretroviral therapy in Haiti. J Int AIDS SOC 2012, 15:17375.

22. Sarang A, Rhodes T, Sheon N: Systemic barriers accessing HIV treatment among people who inject drugs in Russia: a qualitative study. Health Policy and Plan 2013, 28:681-691.

doi:10.1186/1742-6405-11-18

Cite this article as: Chkhartishvili et al: Virologic outcomes of secondline antiretroviral therapy in Eastern European country of Georgia. AIDS Research and Therapy 2014 11:18.

\section{Submit your next manuscript to BioMed Central and take full advantage of:}

- Convenient online submission

- Thorough peer review

- No space constraints or color figure charges

- Immediate publication on acceptance

- Inclusion in PubMed, CAS, Scopus and Google Scholar

- Research which is freely available for redistribution 